\title{
Professor Jacob Plange-Rhule
}

Ghana Med J 2020; 54(2): 75 DOI: http://dx.doi.org/10.4314/gmj.v54i2.3

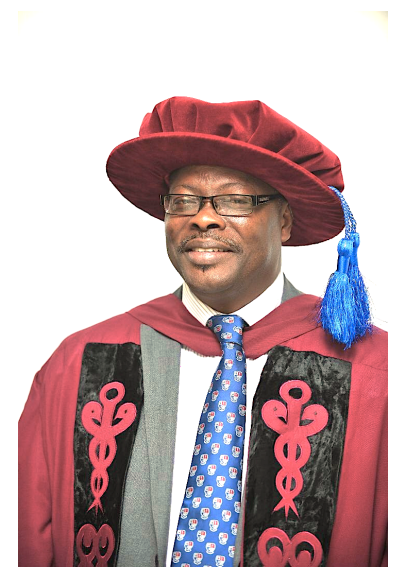

The usual quiet morning of Good Friday, April 10, 2020 , was shattered by the spreading news of the death of Professor Jacob PlangeRhule. For many persons the news elicited sentiments of grief and outpouring of statements on the good nature of the third Rector of the Ghana College of Physicians and Surgeons. Even though he died at the age of 62 years, his footprints will remain in several places where his feet hath trod in academia, medical education, medical 'politics', golf and family life.

Professor Plange-Rhule graduated as a medical doctor from the Kwame Nkrumah University of Science and Technology (KNUST) in 1984. In 1987, he was admitted to the University of Manchester for a PhD course in Physiology which he completed in 1991. He returned to Ghana and was appointed a lecturer in the Department of Physiology at the School of Medical Sciences of KNUST and also Senior Medical Officer at the Komfo Anokye Teaching Hospital, Kumasi. This was the beginning of an enduring career in medical practice, medical education, health research and the welfare of medical practitioners in Ghana.

His students had very favourable things to say about him as a lecturer and mentor. He was seen as a gentle person, ready to listen, encourage and help. His contribution to undergraduate medical education went beyond KNUST. He was external examiner in internal medicine, physiology and dietetics to the University of Ghana, University of Development Studies, University of Cape Coast and the University of The Gambia. He had a long-standing relationship with the Departments of Renal Medicine, General Practice and Primary Care of Saint George's University, London as an Honorary Senior Lecturer. His research work involved international collaborations with colleagues and institutions. His involvement with the Royal College of Physicians of London, of which he was elected a Fellow in 2009, was aimed at finding training opportunities for residents for clinical attachments in the United Kingdom. His involvement in postgraduate medical training involved the Ghana College of Physicians and Surgeons and the West African College of Physicians. He was a Fellow of both Colleges.
Professor Plange-Rhule's academic and clinical practice hub was non-communicable diseases, particularly, hypertension, nephrology and obesity. He was instrumental in the establishment of the Ghana Kidney Association in 2011 and was elected President from 2014 to 2017.

At the turn of the millennium, when the groundswell for the establishment of the Ghana College of Physicians and Surgeons was at its peak, his paper on the distribution of specialists in Ghana was one of the driving points for the establishment of the Ghana College. He was a member of the National Taskforce for the establishment of the Ghana College of Physicians and Surgeons, an institution he eventually came to head as Rector in 2015.

In 1999, he was elected Vice President of the Ghana Medical Association. Two years later, in 2001, he became the President of the mouthpiece of medical practitioners and dentists in Ghana. Those were times when members of the health profession were asking for better remuneration for their services. As a member and later Chairman of the Negotiations Committee of the Association, many of the issues were resolved. Similarly, he was involved in the setting up of the GMA Fund, a pension fund for members of the Association, as a member and later Chairman of the Board of Trustees.

Outside medicine and academia, he served on the Prisons Council of Ghana for a number of years and also on the Board of the MTN Foundation. He was a committed golfer and will not miss an opportunity to invite friends and visitors to join him in a game.

The staff of the Ghana College of Physicians and Surgeons described him as "a unique leader with a great level of humility and love for humanity", "in good times and bad times he never lost his capacity to smile or laugh" and many more of such recollections. There is also the recognition of his work ethic and respect for administrative procedures. During his term as Rector, he carried the programmes of the College forward championing curricular reforms, harmonization with the West African Colleges of Physicians, and Surgeons, introduction of a new diploma course, accessing government support for scholarships for residents and the refurbishment of the hospitality wing of the College building.

He left behind his wife and three lovely daughters.

\section{Professor David Ofori-Adjei FGA, FGCP \\ Editor-in-Chief, Ghana Medical Journal}

